\title{
Randomised prospective comparative analysis of functional outcome of osteosynthesis of intra-articular distal humerus fracture using triceps reflecting and transolecrenon approach
}

\author{
Nuthan Jagadeesh, Nibin Sanil*, Vishwanath M. S.
}

Department of Orthopedics, Vydehi Institute of Medical Sciences, Bangalore, Karnataka, India

Received: 12 April 2020

Revised: 27 April 2020

Accepted: 28 April 2020

\section{*Correspondence:}

Dr. Nibin Sanil,

E-mail: nibinsanil@yahoo.com

Copyright: () the author(s), publisher and licensee Medip Academy. This is an open-access article distributed under the terms of the Creative Commons Attribution Non-Commercial License, which permits unrestricted non-commercial use, distribution, and reproduction in any medium, provided the original work is properly cited.

\section{ABSTRACT}

Background: Intra articular fractures of distal humerus is one of the demanding injuries to manage due to its complex anatomy. Open reduction internal fixation is able to achieve painless, stable and mobile joint. This study is aimed at comparing functional outcome of patients treated with triceps reflecting and olecranon osteotomy approach.

Methods: A hospital based randomized comparative study of 40 patients who diagnosed with distal humerus intraarticular fracture admitted in our hospital from April 2017 to March 2019. Triceps reflecting approach (group A) was used in 20 patients and olecranon osteotomy approach (group B) in 20 patients. Elbow range of movements and Mayo elbow performance score (MEPS) was used to compare outcome.

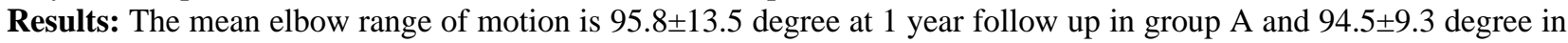
1 year follow up at 1 year follow up in group B. The mean MEP score at end of 1 year in group A was $93.8 \pm 2.9$ and in group B was 91.5 \pm 3.2 shows excellent results but there was no statistically significant difference between MEP scores of two groups. We observed 6 patients developed extension lag less than 10 degree in group A which was clinically insignificant to patients and 7 patients developed hardware prominence in group B.

Conclusions: Triceps reflecting Bryan Morrey approach is equally effective as olecranon osteotomy approach in treatment of distal humerus intra articular fracture with less complication and operative time.

Keywords: Intra-articular distal humerus fracture, Mayo elbow score, Tricep reflecting approach, Olecrenon osteotomy

\section{INTRODUCTION}

Distal humerus intra articular fracture is one of the most difficult and demanding injuries to manage due to its complex anatomy and osteoporotic bone. It constitutes one third of all adult elbow fractures and 1-3\% of all fractures. ${ }^{1,2}$ Management of distal humerus fracture still remains a significant dilemma despite various methods of surgical procedures and recent advances. ${ }^{3}$ They have a bi modal age distribution, which occur in two ways, low energy fall characteristically seen in females aged 80 years and older such as fall from a standard height and in younger adults males aged 12 to 19 years due to motor vehicle collision, fall from height, industrial accidents. ${ }^{4}$ Non-operative management of comminuted distal humerus fractures should be considered only in elderly patients who wants to avoid surgical risks due to comorbidities and have low functional demand. ${ }^{5}$ Thus operative management remains treatment modality of choice in most patients with these fractures. ${ }^{2,6}$

Selection of surgical approach still remains a debatable topic and there is no clear-cut standard surgical approach for treatment of intra articular fractures of distal humerus. Posterior approach to elbow is more commonly used 
owing to reduced risk of damage to vital structures, better visualization of articular surface and less bleeding. Various modification of posterior approach used for better visualization of articular surface include olecranon osteotomy, triceps reflecting (Bryan Morrey), triceps splitting (Campbell) and triceps reflecting anconeus pedicle approaches. Olecranon osteotomy provides better exposure but have potential disadvantages like delayed union, non-union and hardware problem. ${ }^{7-12}$ Many variations of the triceps reflecting approach have been reported. These approaches all involve complete reflection of the triceps osteoperiosteal sleeve from the proximal ulna to expose the distal humerus articular surface. The classic Bryan Morrey medial-to-lateral triceps reflecting approach has been used to successfully treat complex intra articular fractures of the distal humerus, but the approach has been associated with extensor mechanism weakness or failure and ulnar nerve dysfunction. ${ }^{13-17}$ The triceps-reflecting anconeus pedicle (TRAP) approach also involves medialto-lateral reflection of the triceps insertion but adds a modified Kocher approach that preserves the lateral collateral and annular ligaments while elevating the anconeus from the ulna. ${ }^{18}$ The available options for osteosynthesis of distal humerus fractures are plate, screws and k-wires. Total elbow replacement is rarely considered. Anatomical pre-contoured locking compression plates, reconstruction plate is usually used for plate osteosynthesis fixing both columns of distal humerus. Aim of treatment is to achieve a painless, stable and mobile joint to perform activities of daily living. ${ }^{6}$

In this study we compare the outcome of two surgical techniques, triceps reflecting approach and trans olecranon approach, for the osteosynthesis of distal humerus intra articular fractures.

\section{METHODS}

This randomised prospective longitudinal study involves 40 patients with distal humerus intra articular fracture who fit into inclusion criteria, admitted in Vydehi Medical College and Research Centre Bangalore from April 2017 to March 2019. The cohort was randomized based on odd/even number. 40 patients were divided into two groups with odd numbers (group A) assigned to fractures treated with triceps reflecting approach and even number (group B) assigned to fractures treated with olecranon osteotomy approach. Local ethical committee approval taken for study.

Patients with intra-articular distal humerus fractures in a skeletally matured bone who are medically fit for surgery are included. Patients with open physis, pathological fractures, associated vascular injuries, cognitive disorders and patients who are medically unfit for surgery are excluded. Patient with extra articular distal humerus i.e., AO type A and B are excluded. Patients fitting inclusion criteria are admitted after initial management in casualty. Patients from the inclusion criteria were subjected to history taking, through physical examination and later evaluated for any radiological (X-ray of elbow AP and lateral views) evidence of intra articular fracture distal humerus. CT scan was done to delineate fracture pattern and fracture classified according to AO classification. Before subjecting the patients for investigations and surgical procedures written/informed consent was obtained from each patient. All patients were given general anaesthesia along with supraclavicular block and were positioned in the lateral position with involved limb supported over the bolster. Both groups were operated under sterile precaution. All the patients underwent orthogonal platting internal fixation and stabilization using $3.5 \mathrm{~mm}$ LCP.

\section{Operative technique}

All patients were operated on lateral position. No tourniquet was used. The standard surgical steps were followed. All patient was administered a dose of third generation cephalosporins just before the surgery. Elbow was exposed posteriorly, 10-15 cm mid line skin incision slightly curved radially over the olecranon was used in either case, full thickness fasciocutaneous flaps were elevated to expose olecranon and triceps tendon. Ulnar nerve isolated and protected. These steps were common to both groups.

\section{Triceps reflecting (Bryan Morrey) approach}

After identification of the ulnar nerve, a periosteal incision was made on the medial aspect of the ulna. By sharp dissection of the triceps insertion (Sharpey's fibers), a flap including the triceps, forearm fascia, and ulnar periosteum was progressively raised. The extensor mechanism was reflected laterally; the anconeus was identified and included in the tendon-periosteal flap, which was finally dislocated on the lateral side of the denuded olecranon; 2 transverse drill holes were then made in the olecranon, with a $2.7 \mathrm{~mm}$ drill for later closure by osteoperiosteal trans osseous sutures across the ulna. Articular fragments of the distal block were reduced under direct visualization and temporarily fixed with $\mathrm{k}$ wire and CC screws. Medial and lateral pillars were reconstructed using pre-contoured anatomical distal humerus plate. Distal humerus plates were placed on dorso-laterally and medially in an orthogonal fashion fixed with appropriate locking screws or non-locking screws. Extensor mechanism repair was done by re position to its anatomic position along the posterior elbow using trans-osseous absorbable sutures using drill holes made earlier. Stability checked; closure is done in layers after anterior transposition of ulnar nerve (Figure 1a).

\section{Olecranon osteotomy approach}

Proximal ulna exposed. A standard chevron osteotomy was done $2 \mathrm{~cm}$ from tip of the olecranon using oscillating saw. The osteotomized olecranon fragment was elevated proximally along with triceps tendon. Fracture reduction and fixation principles after exposure was similar in both 
techniques. Osteotomized fragment was fixed with tension band wiring, screw/tension band construct. Anatomical reduction was checked, closure is done in layers after anterior transposition of ulnar nerve (Figure 1b).

\section{Post-operative care}

All patients received IV antibiotics for 3 days. A removable above elbow slab applied on $90^{\circ}$ flexion was given for patients of both groups for two weeks. Active assisted elbow movements were started on post op day 2 . Stiches removed on post op day 14. Patients were advised to attend orthopaedic OPD for follow up at six weeks, three months, six months, one year and two years after surgery. Minimum follow up period of six months was required to be included. Clinical and functional improvement was assessed using Mayo elbow performance score (MEPS).$^{20}$ Pain was measured in terms of visual analog scale (VAS) pain score. ${ }^{21}$ Radiological parameters were assessed on Xray films of elbow (AP and lateral view). Complications were assessed with patient's complaints, clinical examination, radiological and laboratory investigations.

\section{Mayo elbow performance score $e^{20}$}

Pain intensity: None - 45, mild - 30, moderate - 15 , severe - 0 .

Range of motion: Arc of motion greater than $100^{\circ}-20$, arc of motion between $50^{\circ}$ and $100^{\circ}-15$, arc of motion less than $50^{\circ}-5$.

Stability: Stable - 10, moderate instability - 5, grossly unstable - 0 .

Function: Can comb hair - 5, can eat food - 5, can wear shoes - 5 , can perform hygiene - 5 , can wear shirt - 5 .

Mayo elbow score: Score greater than 90: excellent, score 75 to 89: good, score 60 to 74: fair, score less than 60: poor.
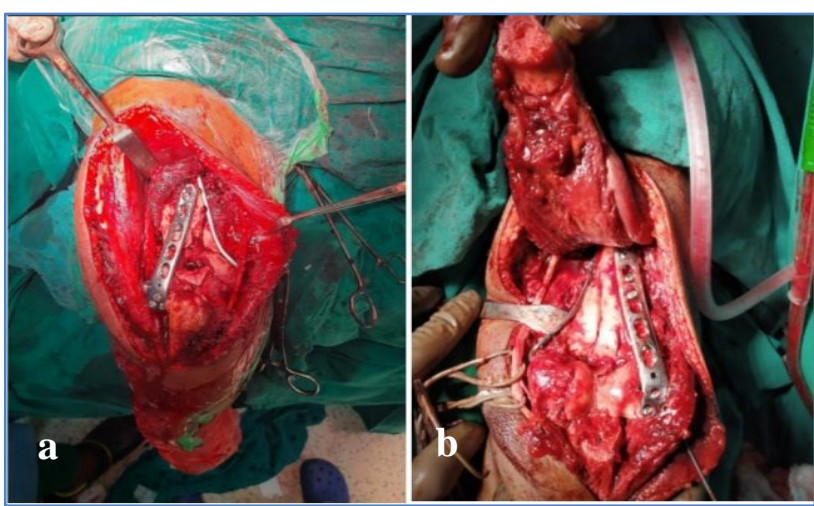

Figure 1: Surgical technique used (a) triceps reflecting (Bryan Morrey) approach and (b) olecranon osteotomy approach.

\section{Statistical analysis}

All characteristics were summarized descriptively. For continuous variables, the summary statistics of mean \pm standard deviation (SD) were used. For categorical data, the number and percentage were used in the data summaries and diagrammatic presentation. Chi-square $\left(\chi^{2}\right)$ test was used for association between two categorical variables. The difference of the means of analysis variables between two independent groups was tested by unpaired $t$ test. The difference of the means of analysis variables between more than two independent groups was tested by ANOVA and $F$ test of testing of equality of Variance. If the p-value was 0.05 , then the results were considered to be statistically significant otherwise it was considered as not statistically significant. Data were analyzed using SPSS software v.23.0. and microsoft office 2007.

\section{RESULTS}

Total of 40 patients (20 in each group) were evaluated for the study.

\section{Demographic}

Both groups had predominantly male patients i.e., $80 \%$ of group A and $70 \%$ of group B. Mean age in group A was $43 \pm 12.4$ years (range 22-64 years) and group B was $40.3 \pm 13.1$ years (range 19-68 years) (Table 1 ).

\section{Laterality}

Right side was injured in $65 \%$ in triceps reflecting approach and $60 \%$ in olecranon osteotomy approach (Table 2).

\section{Type of fracture}

Only intra articular distal humerus fractures are included with $60 \%$ belonging to $C 1,30 \%$ belonging to $C 2$ and $10 \%$ of $\mathrm{C} 3$ type in group $\mathrm{A}$ and $50 \%$ belong to $\mathrm{C} 1,40 \%$ belong to $\mathrm{C} 2$ and $10 \%$ belong to $\mathrm{C} 3$ type in group B (Table 2).

\section{Mode of injury}

$50 \%$ and $45 \%$ of the patients had road traffic accident in group A and group B (Table 2).

\section{Duration of surgery}

$55 \%$ of surgeries took time between $60-120$ minutes in group A and $85 \%$ in group B took time between $60-120$ minutes (Table 2).

\section{Follow up}

Minimum follow up required for inclusion was set at 6 months but more than $70 \%$ of our patients were available for follow up period of more than 1 year. Mean follow up was $15 \pm 3.2$ months for group A and $16 \pm 3.6$ months. 


\section{Elbow range of motion}

The mean elbow range of motion is $95.8 \pm 13.5$ degree at 1 year follow up and $106.3 \pm 11.1$ degree in 2 years follow up in group $\mathrm{A}$ and $94.5 \pm 9.3$ degree in 1 year follow up at 1 year follow up and 101.3 \pm 13.2 degree in group B (Table $3)$.

\section{MEP score}

The mean MEP score at end of 1 year in group A was $93.8 \pm 2.9$ and in group B was $91.5 \pm 3.2$ shows excellent results and there was no statistically significant difference between MEP scores of two groups. 14 out 20 patients and 12 out of 20 patients showed excellent outcome in group $\mathrm{A}$ and $\mathrm{B}$ respectively (Table 4 and 5).

Table 1: Distribution of demographic variables between study groups.

\begin{tabular}{|c|c|c|c|c|c|c|}
\hline \multirow{2}{*}{ Sex } & \multicolumn{2}{|c|}{ Triceps reflecting } & \multicolumn{2}{|c|}{ Olecranon osteotomy approach } & \multirow{2}{*}{$\begin{array}{l}\text { Chi square } \\
\text { value }\end{array}$} & \multirow{2}{*}{$P$ value } \\
\hline & $\mathbf{N}$ & $\%$ & $\mathbf{N}$ & $\%$ & & \\
\hline Male & 16 & 80.0 & 14 & 70.0 & \multirow{2}{*}{0.533} & \multirow{2}{*}{0.465} \\
\hline Female & 4 & 20.0 & 6 & 30.0 & & \\
\hline \multirow{2}{*}{ Age (years) } & Mean & SD & Mean & SD & $t$ value & $P$ value \\
\hline & 43.0 & 12.4 & 40.3 & 13.1 & 0.682 & 0.499 \\
\hline
\end{tabular}

Table 2: Distribution of selected variables between study groups.

\begin{tabular}{|c|c|c|c|c|c|c|}
\hline \multirow{2}{*}{ Parameter } & \multicolumn{2}{|c|}{ Triceps reflecting } & \multicolumn{2}{|c|}{ Olecranon osteotomy approach } & \multirow{2}{*}{$\begin{array}{l}\text { Chi square } \\
\text { value }\end{array}$} & \multirow{2}{*}{ P value } \\
\hline & $\mathbf{N}$ & $\%$ & $\mathbf{N}$ & $\%$ & & \\
\hline \multicolumn{7}{|l|}{ Side } \\
\hline Right & 13 & 65.0 & 12 & 60.0 & \multirow{2}{*}{0.107} & \multirow{2}{*}{0.744} \\
\hline Left & 7 & 35.0 & 8 & 40.0 & & \\
\hline \multicolumn{7}{|l|}{ Mode of injury } \\
\hline RTA & 10 & 50.0 & 9 & 45.0 & \multirow{3}{*}{0.111} & \multirow{3}{*}{0.946} \\
\hline Fall & 8 & 40.0 & 9 & 45.0 & & \\
\hline Other & 2 & 10.0 & 2 & 10.0 & & \\
\hline \multicolumn{7}{|l|}{ AO type } \\
\hline Simple articular & 12 & 60.0 & 10 & 50.0 & \multirow{3}{*}{0.468} & \multirow{3}{*}{0.792} \\
\hline Partial articular & 6 & 30.0 & 8 & 40.0 & & \\
\hline Complete articular & 2 & 10.0 & 2 & 10.0 & & \\
\hline \multicolumn{7}{|c|}{ Duration of surgery (minutes) } \\
\hline $1-60$ & 0 & 0.0 & 0 & 0.0 & \multirow{3}{*}{4.286} & \multirow{3}{*}{$0.038^{*}$} \\
\hline $60-120$ & 11 & 55.0 & 17 & 85.0 & & \\
\hline$>120$ & 9 & 45.0 & 3 & 15.0 & & \\
\hline \multicolumn{7}{|l|}{ Blood loss (ml) } \\
\hline $0-200$ & 17 & 85.0 & 11 & 55.0 & \multirow{4}{*}{4.397} & \multirow{4}{*}{0.111} \\
\hline $200-400$ & 2 & 10.0 & 7 & 35.0 & & \\
\hline$>400$ & 1 & 5.0 & 2 & 10.0 & & \\
\hline Total & 20 & 100.0 & 20 & 100.0 & & \\
\hline
\end{tabular}

Note: *significant at $5 \%$ level of significance $(\mathrm{p}<0.05)$.

Table 3: Distribution of range of motion between study groups.

\begin{tabular}{|llllllll|}
\hline \multirow{2}{*}{ Range of motion } & \multicolumn{2}{l}{ Triceps reflecting } & \multicolumn{2}{l}{$\begin{array}{l}\text { Olecranon osteotomy } \\
\text { approach }\end{array}$} & \multicolumn{2}{c|}{ t value } & P value \\
\cline { 3 - 8 } & & Mean & SD & Mean & SD & & \\
\hline Pre-operative & & 2.0 & 4.1 & 0.5 & 1.5 & 1.531 & 0.134 \\
\hline \multirow{3}{*}{ Post-operative } & 2 weeks & 56.5 & 17.3 & 70.8 & 12.2 & -3.019 & $0.005^{*}$ \\
\cline { 2 - 8 } & 12 weeks & 80.5 & 12.6 & 85.8 & 6.5 & -1.658 & 0.105 \\
\cline { 2 - 8 } & 6 months & 91.8 & 9.6 & 93.0 & 7.8 & -0.45 & 0.655 \\
\cline { 2 - 8 } & 1 year & 95.8 & 13.5 & 94.5 & 9.3 & 0.341 & 0.735 \\
\cline { 2 - 8 } & 2 years & 106.3 & 11.1 & 101.3 & 13.2 & 0.581 & 0.582 \\
\hline ANOVA p value & $<0.001^{*}$ & & $<0.001^{*}$ & & & \\
\hline
\end{tabular}

Note: *significant at $5 \%$ level of significance $(\mathrm{p}<0.05)$. 
Table 4: Distribution of MEP score between study groups.

\begin{tabular}{|c|c|c|c|c|c|c|}
\hline \multirow{2}{*}{ MEP score } & \multicolumn{2}{|c|}{ Triceps reflecting } & \multicolumn{2}{|c|}{ Olecranon osteotomy approach } & \multirow{2}{*}{ t value } & \multirow{2}{*}{ P value } \\
\hline & Mean & SD & Mean & SD & & \\
\hline 2 weeks & 47.8 & 7.0 & 47.5 & 6.8 & 0.115 & 0.909 \\
\hline 12 weeks & 65.3 & 7.3 & 64.3 & 7.1 & 0.437 & 0.664 \\
\hline 6 months & 76.5 & 2.9 & 76.0 & 4.8 & 0.403 & 0.689 \\
\hline 1 year & 93.8 & 2.9 & 91.5 & 3.2 & 0.794 & 0.432 \\
\hline 2 years & 94.2 & 2.5 & 92.4 & 3.4 & 0.655 & 0.537 \\
\hline ANOVA p value & $<0.001 *$ & & $<0.001 *$ & & & \\
\hline
\end{tabular}

Note: *significant at $5 \%$ level of significance $(\mathrm{p}<0.05)$.

Table 5: Grading of MEP score between study groups.

\begin{tabular}{|lll|}
\hline MEP score & $\begin{array}{l}\text { Triceps } \\
\text { reflecting }\end{array}$ & $\begin{array}{l}\text { Olecranon } \\
\text { osteotomy approach }\end{array}$ \\
\hline Excellent $(>90)$ & 14 & 12 \\
\hline Good $(\mathbf{7 5 - 9 0 )}$ & 5 & 6 \\
\hline Fair $(\mathbf{6 0 - 7 4 )}$ & 1 & 2 \\
\hline Poor $(<\mathbf{6 0})$ & 0 & 0 \\
\hline
\end{tabular}

Table 6: Various complications.

\begin{tabular}{|lll|}
\hline Parameters & $\begin{array}{l}\text { Triceps } \\
\text { reflecting } \\
(\mathbf{n}=\mathbf{2 0})\end{array}$ & $\begin{array}{l}\text { Olecranon osteotomy } \\
\text { approach }(\mathbf{n}=20)\end{array}$ \\
\hline Extensor lag & 6 & 3 \\
\hline $\begin{array}{l}\text { Hard ware } \\
\text { prominence }\end{array}$ & 0 & 7 \\
\hline $\begin{array}{l}\text { Ulnar nerve } \\
\text { neuropraxia }\end{array}$ & 2 & 3 \\
\hline Delayed union & 0 & 1 \\
\hline Non union & 0 & 0 \\
\hline Infection & 1 & 2 \\
\hline
\end{tabular}

\section{Complications}

In group A, 6 patients had developed extensor lag, 2 patients had developed ulnar nerve paraesthesia, 1 patient developed superficial infection and delayed wound healing. In group B, 7 patients presented with complain of hard ware prominence, 3 patients developed extensor lag, 3 patients developed ulnar nerve paraesthesia, 2 patients developed infection and 1 patient presented with delayed union at osteotomy site 6 months.

\section{DISCUSSION}

Distal humerus are complex injuries with associated fragmentation, bony instability and soft tissue injury. Conservative treatment has largely been abandoned because of its unsatisfactory results. Open reduction internal fixation is the golden standard of treatment and olecranon osteotomy approach was the most preferred technique because of better exposure. Other techniques used are TRAP approach, triceps reflecting, triceps splitting approach etc. The goal of treatment is to achieve painless, stable and mobile joint. Careful pre-operative planning and aggressive post-operative rehabilitation are essential for better outcome.

In our study, total of 40 patients were included in the present study, the mean age distribution of group A was $43 \pm 12 \mathrm{SD}$ and mean age distribution of group $\mathrm{B}$ was $40 \pm 13.1 \mathrm{SD}$, there were 30 males (16 males in group A and 14 males in group B) and 10 females (4 in group A and 6 in group B). Most common mode of injury was road traffic accident, out of 20 patients in group A, 10 patients got injured by road traffic accident while 9 patients got injured from road traffic accident and fall in Group B. In both group right side was most affected. So, there was no significant difference among two groups in-terms of demographic variables.

The minimum duration of surgery in each group was between 60 minutes to 120 minutes and considerably more time was required in osteotomy group ( $\mathrm{p}$ value: 0.038 ) considering time required to fix the olecranon osteotomy which was spared in triceps reflecting group. Though we had put trans osseous sutures to fix extensor mechanism, this hardly took couple of more minutes of closure. Predrilling the holes in olecranon made trans osseous suturing simple. Blood loss was also significantly more in osteotomy group, this can attribute olecranon osteotomy site which is cancellous area causing more bleeding.

Gupta et al conducted a comparative study of different approach for open reduction and internal fixation in fractures of distal humerus. A total of 60 patients operated with olecranon osteotomy approach, Bryan Morrey approach and Campbell's approach in a span of 2 years. The mean age for Bryan Morrey approach was 37.5 and olecranon approach was 37 years. They said visibility of fracture site in olecranon osteotomy approach was far better than Bryan Morrey approach. MEPS score was highest in patients operated with olecranon osteotomy 18 patients out of 20 patients whereas 8 cases in Bryan Morrey approach had excellent results. However, when the mean results of these group were statistically analyzed, the results were statistically insignificant and there was no statistical difference in complication rate among the groups. $^{22}$

In our study, analysis of range of motion and MEPS score revealed there was no significant difference on comparing 
both groups. Mean range of motion in triceps reflecting group was $106.3 \pm 11^{\circ}$ and in osteotomy group $101.3 \pm 13^{\circ}$ in group B. The average mayo elbow performance score at end of 1 year in group A was $93.8 \pm 2.9$ and in group B was 91.5 \pm 3.2 . 14 out 20 patients and 12 out of 20 patients showed excellent outcome in group A and B respectively (Figure 2 and 3). We could obtain enough exposure with Bryan Morrey approach to fix the fracture without any difficulty. One of main reasons for inadequate exposure in Bryan Morrey's approach is not developing a long osteoperiosteal sleeve during reflecting triceps mechanism. This not only affects exposure but also increases tension on extensor mechanism leading to tears in triceps insertion which ultimately reduces the strength of elbow extension. Even though our findings are in contrast to Gupta et al, the statistically results obtained by them were also not significant. This is further supported by study conducted by Krishna et all who conducted a comparative study of olecranon osteotomy approach and triceps reflecting approach in osteosynthesis of distal humerus fracture in adults. ${ }^{22} \mathrm{~A}$ total of 40 patients were alternatively allotted into two different groups, group A had 20 patients treated by olecranon osteotomy and group $\mathrm{B}$ had 20 patients treated by triceps reflecting approach and followed up for a period of 24 months. The mean MEPI score was 90 points and 93 points respectively indicating mild impairment and the mean of range of motion was $97^{\circ}$ and $103^{\circ}$, states that, trans olecranon and triceps reflecting approaches are similar in the functional outcomes but complication rates are higher in trans olecranon approach with best exposure, a triceps reflecting approach may be selected to reduce complications.
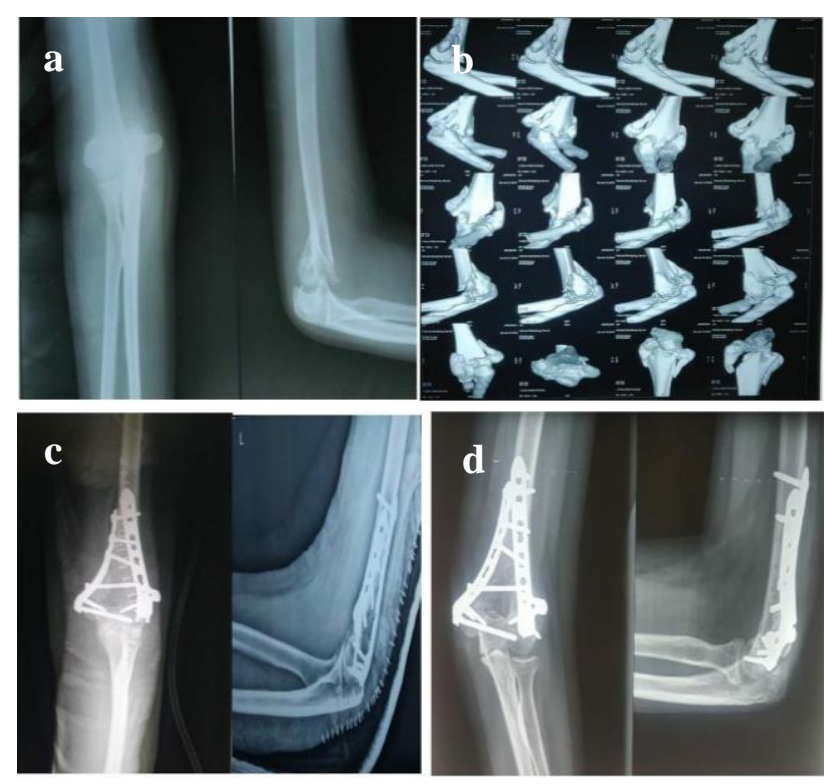

Figure 2: 22 years old with intraarticular fracture distal humerus AO type $\mathrm{C} 1$ operated through triceps reflecting approach; (a) preoperative X-ray, (b) pre-operative CT with 3D reconstruction, (c) immediate post-operative $X$ ray, and (d) 1 year follow up X-ray.
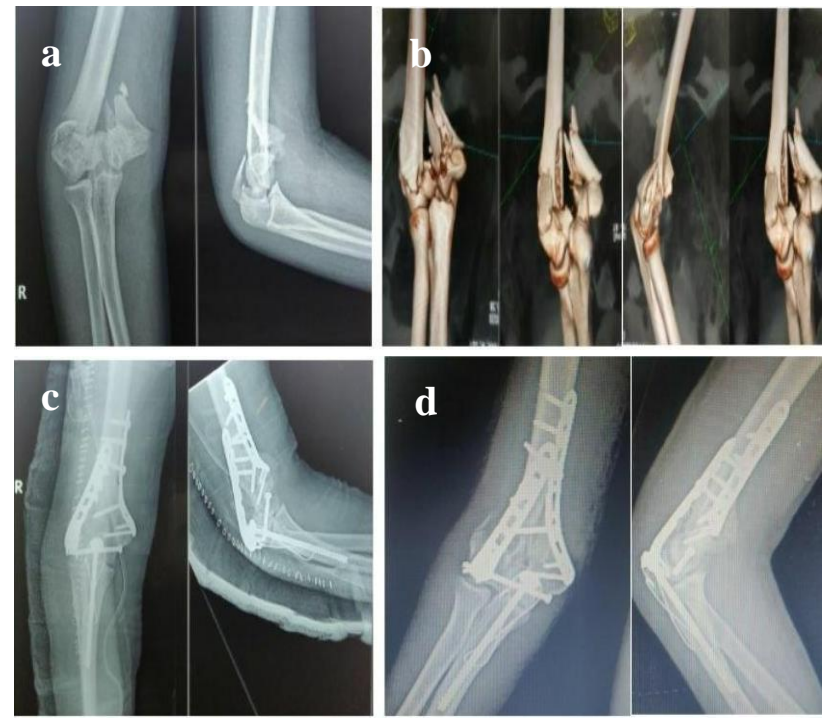

Figure 3: 47 years old with intraarticular fracture distal humerus $\mathrm{AO}$ type $\mathrm{C} 3$ operated through transolecrenon approach; (a) preoperative $\mathrm{X}$-ray, (b) CT scan 3D reconstruction, (c) immediate post-operative, and (d) follow $X$ ray.
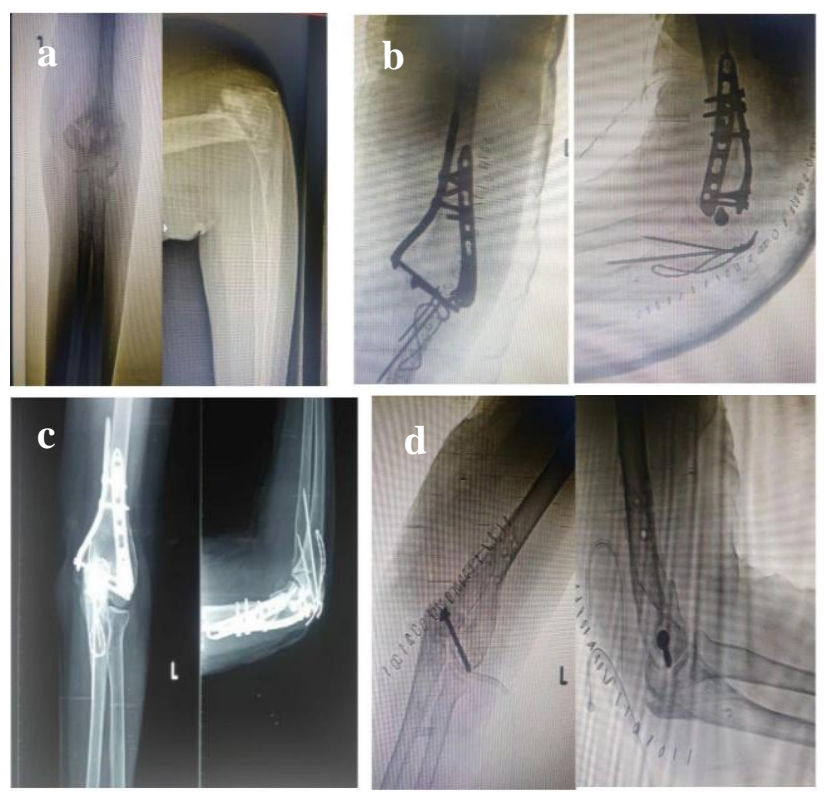

Figure 4: Implant removal done at 12 months follow up due to hardware impingement and prominence at olecranon tip (CC screw could not be removed); (a) pre-operative $X$-ray, (b) postoperative X-ray, (c) follow up X-ray, and (d) implant removal done due to complaints of hardware impingement.

Complications are common in the management of distal humerus fractures and include elbow stiffness, heterotopic ossification, non-unions, neuropathies, and infections. Post-traumatic elbow stiffness can arise from both intrinsic 
and extrinsic sources. Intrinsic causes of stiffness include joint adhesions, synovitis, articular incongruity, and intraarticular loose bodies. Extrinsic causes include capsular contractures and hetero-topic ossification. Loss of some motion is expected after distal humerus fractures, particularly terminal extension. In our study, the main complication encountered in triceps reflecting group was extension lag in 6 patients which was less than $10^{\circ}$ in all of them. But none of the patients had any functional disability due to extension lag of less than 10 degree. Even though we were vigilant in recording extension lag as complications, in a patient perspective they did not any issues related to surgery.

But common complication related to osteotomy group was hardware prominence especially at tip of olecranon which was seen in 7 patients (Figure 4). This is attributed to limited soft tissue cover at olecranon tip. 2 and 3 patients developed ulnar nerve neuropraxia in group A and group $\mathrm{B}$ who all recovered with time and methyl cobalamine supplements. We prescribed indomethacin $75 \mathrm{mg}$ daily for 4 weeks along with guided physiotherapy, thus none of our patients developed any heterotopic calcification. There were no instances of non-union with most patients showing radiological signs of union by 16-20 weeks. There was one case of delayed union with responded to bone marrow injection at 20 weeks.

\section{CONCLUSION}

Though olecranon osteotomy or trans olecranon approach is one of the common approaches used for intra-articular distal humerus fracture fixation, other approaches like triceps reflecting (Bryan Morrey approach) are equally effective not only in providing adequate exposure but also in providing excellent functional outcome. Common complication like hardware prominence, non-union of osteotomy site seen in transolecrenon approach are not seen in triceps reflecting approach. Operating time is also significantly less in triceps reflecting approach and doesn't require a long learning curve to learn this approach. Thus, triceps reflecting approach can be the preferred approach in fixation of intraarticular fractures of distal humerus when compared to transolecrenon approach.

Funding: No funding sources

Conflict of interest: None declared

Ethical approval: The study was approved by the institutional ethics committee

\section{REFERENCES}

1. Rose SH, melton LJ, Morrey BF, Ilstrup DM, Riggs BL. Epidemiologic features of distal humral fracture. Clin Orthop Relat Res. 1982;168:24-30.

2. Palvanen M, Kannus P, Niemi S. Secular trends in the osteoporotic fractures of the distal humerus in elderly women. Eur J Epidemiol. 1998;14(2):159-64.
3. Islam SU, Glover AW, Waseem M. Challenges and Solutions in Management of Distal Humerus Fractures. Open Orthop J. 2017;11(1):1292-307.

4. Robinson CM, Hill RM, Jacobs N. Adult distal humeral metaphyseal fractures: epidemiology and results of treatment. J Orthop Trauma. 2003;17(1):38-47.

5. Batten TJ, Hidge SC, Brinsden MD, Guyver PM. Non-operative management of distal humerus fractures in the elderly: a review of functional outcomes. Eur J Orthop Surg Traumatol. 2018;28(1):23-7.

6. Brown CCM. Rockwood and Greens fractures in adults. Philadelphia: Wolters Kluwer; 2015.

7. Henley MB. Intra-articular distal humeral fractures in adults. Orthop Clin North Am. 1987;18:11-23.

8. Jupiter JB, Neff U, Holzach P, Allgower M. Intercondylar fractures of the humerus. An operative approach. J Bone Joint Surg. 1985;67:226-39.

9. McKee MD, Wilson TL, Winston L, Schemitsch EH, Richards RR. Functional outcome following surgical treatment of intra-articular distal humeral fractures through a posterior approach. J Bone Joint Surg. 2000;82:1701-7.

10. Cheung EV, Steinmann SP. Surgical approaches to the elbow. J Am Acad Orthop Surg. 2009;17:325-33.

11. Gofton WT, Macdermid JC, Patterson SD. Functional outcome of AO type C distal humeral fractures. J Hand Surg Am. 2003;28:294-308.

12. Holdsworth BJ, Mossad MM. Fractures of the adult distal humerus. Elbow function after internal fixation. J Bone Joint Surg Br. 1990;72:362-5.

13. Sodergard J, Sandelin J, Bostman O. Postoperative complications of distal humeral fractures. 27/96 adults followed up for 6 (2-10) years. Acta Orthop Scand. 1992;63:85-9.

14. Pierce TD, Herndon JH. The triceps preserving approach to total elbow arthroplasty. Clin Orthop Relat Res. 1998;354:144-52.

15. Celli A, Arash A, Adams R, Morrey BF. Triceps insufficiency following total elbow arthroplasty. J Bone Joint Surg Am. 2005;87:1957-64.

16. Hildebrand KA, Patterson SD, Regan WD, MacDermid JC, King GJ. Functional outcome of semi-constrained total elbow arthroplasty. J Bone Joint Surg Am. 2000;82:13791386.

17. Ek ET, Goldwasser M, Bonomo AL. Functional outcome of complex intercondylar fractures of the distal humerus treated through a triceps-sparing approach. J Shoulder Elbow Surg. 2008;17:441-6.

18. Driscoll OSW. The triceps-reflecting anconeus pedicle (TRAP) approach for distal humeral fractures and non-unions. Orthop Clin North Am. 2000;31:91101.

19. Mayo Elbow Performance Score. J Orthop Trauma. 2006;20(8):127.

20. McCormack HM, Horne DJ, Sheather S. Clinical applications of visual analogue scales: a critical review. Psychol Med. 1988;18:1007-19.

21. Gupta G, Ghosh S, Chaudhuri A, Datta S, Dutta S, Dugar N. Comparative study of different approaches 
for open reduction and internal fixation in fractures of distal humerus. Saudi J Sports Med. 2015;15:6873

22. Krishna RK, Aradhana TR, Preetham N. A comparative study of olecranon osteotomy approach and triceps reflecting approach in osteosynthesis of distal humerus fracture in adults. Indian J Orthop Surg. 2015;1(1):60-3.
Cite this article as: Jagadeesh N, Sanil N, Vishwanath MS. Randomised prospective comparative analysis of functional outcome of osteosynthesis of intra-articular distal humerus fracture using triceps reflecting and transolecrenon approach. Int J Res Orthop 2020;6:722-9. 